\title{
Ação antiproliferativado flavonoide morina e do extrato da folha de oliveira (Oleaeuropaea L.) contra a linhagem de célula H460
}

PEREIRA, W.L. ${ }^{*}$; OLIVEIRA, T.T. ${ }^{*}$; KANASHIRO, M. ${ }^{2}$; COSTA, M.R. ${ }^{1}$

${ }^{1}$ Departamento de Bioquímica e Biologia Molecular,UFV, Av. PH Holfs, sem número, Viçosa, MG, 36570-000.'Laboratório de Biologia do Reconhecer, Centro de Biociências e Biotecnologia, UENF, Av. Alberto Lamego, 2000 - Parque Califórnia,Campos dos Goytacazes, RJ, 28013-602. *Autores para correspondência: wolope9@gmail.com, ttolodo@ufv.br

RESUMO: O presente estudo investigou a indução de morte celular por apoptose pelo flavonóide morina e pelo extrato da folha de oliveira (Oleaeuropaea L.) em linhagens de células de câncer de pulmão do tipo não pequenas ( $\mathrm{H} 460)$. O tratamento com morina e o extrato de oliveira em células $\mathrm{H} 460$ resultou na redução do crescimento tumoral e indução de morte celular avaliados pelos ensaios de MTT e lactato desidrogenase (LDH) e a morte celular por apoptose confirmada por microscopia de fluorescência e análise por citometria de fluxo. Os dados indicaram que o flavonóide morina e o extrato de oliveira diminuíram a viabilidade celular para taxas percentuais de $7,22 \pm 1,54 \%$ e $62,37 \pm 2,85 \%$ nas concentrações de $800 \mu \mathrm{M}$ e $\mu \mathrm{g} / \mathrm{mL}$, respectivamente. As maiores taxas percentuais de morte celular por apoptose foram $100 \%$ para morina na concentração de $800 \mu \mathrm{M}$ e $70,49 \pm 5,91 \%$ para o extrato de oliveira na concentração de $800 \mu \mathrm{g} /$ $\mathrm{mL}$. Estes resultados foram associados com a alteração do potencial de membrana mitocondrial, cujos valores são de $54,91 \%$ para morina na concentração de $400 \mu \mathrm{M}$ e $42,2 \%$ para o extrato de oliveira na concentração de $800 \mu \mathrm{g} / \mathrm{mL}$ sugerindo envolvimento da via intrínseca da morte celular por apoptose. Portanto, morina e o extrato de oliveira afetaram a viabilidade celular da linhagem $\mathrm{H} 460$ induzindo morte celular por apoptose.

Palavras-chave: Linhagens de células H460, morina, extrato de oliveira, atividade antitumoral.

\begin{abstract}
The antiproliferative action of morin flavonoid and olive leaf extract (Olea europaea L.) against the cell line $\mathbf{H 4 6 0}$. This study investigates possible apoptosis induction mechanism by the flavonoid morin and the olive leaf extract (Olea europaea L.) in non-small lung cancer cells (H460). The treatment with morin and olive leaves extract resulted in growth inhibition and induction of apoptosis in $\mathrm{H} 460$ cells lines measured by the MTT assay methods and confirmed by fluorescence microscopy, flow cytometry analysis. The data indicated that themurin and the extract of olive decreased the cell viability percentage rates of $7.22 \pm 1,54 \%$ and $62.37 \pm 2,85 \%$ in the concentrations of $800 \mu \mathrm{M}$ and $\mu \mathrm{g} / \mathrm{mL}$, respectively. The highest percentage rates of cell death by apoptosis were $100 \%$ for themorin in a concentration of 800 $\mu \mathrm{M}$ and $70.49 \pm 5.91 \%$ for the olive extract in a concentration of $800 \mu \mathrm{g} / \mathrm{mL}$. These findings were associated with altered mitochondrial membrane potential, whose value is $54.91 \%$ for the murin concentration of $400 \mu \mathrm{M}$ and $42.2 \%$ for the olive extract in a concentration of $800 \mathrm{mg} / \mathrm{mL}$, suggesting involvement of the intrinsic pathway of cell death by apoptosis. Therefore, the morin and the olive extract affect the cell viability of $\mathrm{H} 460$ cell lines inducing cell death by apoptosis.
\end{abstract}

Keywords: H460 line cell, morin, olive leaf extract, antitumor activity

\section{INTRODUÇÃO}

O câncer de pulmão é a principal causa de morte por câncer no mundo (Hartwell et al.,2011; Yuan et al., 2013; Holenrieder \& Stieber, 2010). No Brasil, a estimativa de novos casos de câncer de pulmão para 2014 é de 27.330 , sendo
16.400 homens e 10.930 mulheres Inca (2014). Histologicamente quase todos os tipos de cânceres de pulmão são de origem epitelial e incluem dois subtipos principais: células pequenas (CPCP) e células não-pequenas (CPNCP) (Hartwell 
et al., 2011). As mutações mais frequentes no câncer de pulmão acontecem nos genes supressores de tumores P53, que codificam a proteína p53, reguladora do ciclo celular (Mountzios et al., 2008; Blum et al., 2011).

Ao longo dos últimos anos, existe um crescente interesse em compostos fitoquímicos com potencial anticâncer e baixa toxicidade (Attoub et al., 2011). Vários estudos classificam os flavonoides, compostos polifenólicos, como inibidores de câncer por apresentar atividades antioxidantes, controlar a proliferação celular, bloquear a angiogênese, modular enzimas do metabolismo carcinogênico e detoxificação de carcinógenos (Hung et al., 2010; Amado et al., 2011; Pick et al., 2011).

Morina (2',3,4, '5,7-pentahidroxifavona) é uma flavonol isolado a partir de vários espécies vegetais, como por exemplo na Chloroforatinctoria, Prumusdulcisraphanussativus L., Lepidiumsativum L., Cayluseaabyssinica, alem de outras espécies de plantas da família moraceae (Tamiru et al., 2012). Este flavonoide exibe vários efeitos biológicos e bioquímicos incluindo atividades antioxidante, antiproliferativa, antineoplásica, anti-inflamatóriae cardioprotetora (Figura 01) (Al-Numair et al., 2012; Naso et al., 2013).

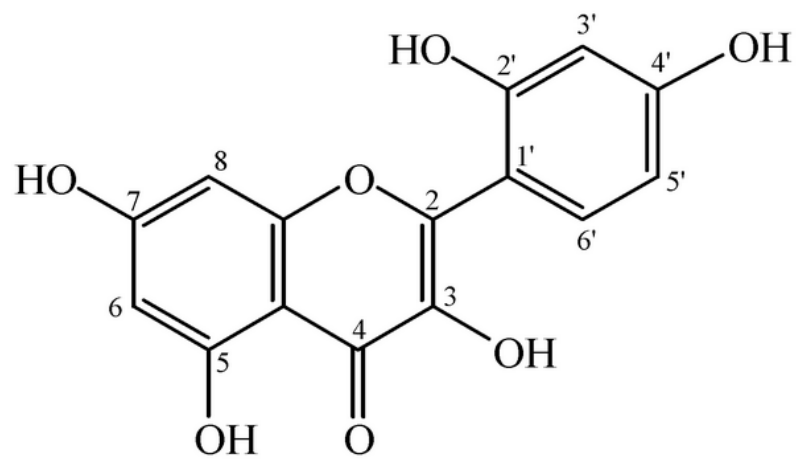

FIGURA 1. Estrutura da morina (Lianda \& Castro, 2008).

As folhas da oliveira (Oleaeuropaea L.) têm sido usadas por mais de 100 anos com propósito medicinal e foram introduzidas recentemente na Farmacopeia PhEur 5 (Kaeidi et al., 2011). As principais substâncias da folha de oliva são oleuropeína, hidroxitirosol, tirosol, luteolina, luteolina-7-glicosilada, rutina, diosmetina, diosmetina 7-glicosilada, ácido caféico, ácido p-cumárico, ácido vanílico, valinina, apigenina 7-glicosilada, (Isik et al., 2012). Oleuropeina e seus derivados, tais como hidroxitirosol, tirosol, são os componentes mais abundantes na folha de oliveira e apresentam atividade antioxidante e inibem o crescimento tumoral de vários cânceres (Bulotta et al., 2014). As ações farmacológicas do flavonoide morina e do extrato de oliveira têm sido pesquisadas em diversas doenças degenerativas pelo laboratório de Biofármacos do Departamento de Bioquímica e Biologia Molecular da UFV. Por este motivo, este trabalho tem como objetivo a avaliação da atividade antineoplásica do flavonóide morina e o extrato de folhas de oliveira contra à linhagem de câncer de pulmão do tipo não pequenas células $(\mathrm{H} 460)$ in vitro.

\section{MATERIAIS E MÉTODOS Materiais}

As folhas de plantas adultas de oliveira, nome científico Oleaeuropaea L., família botânica Oleaceae, foram coletadas em abril de 2012 encontrada na Fazenda Jardim das Oliveiras, estrada Araponga Estouro, s/n Córrego São Gabriel, 2040 oS/42 25 W, localizada no sudeste do estado de Minas Gerais com o auxílio de tesoura de poda. Amostras foram depositadas no herbário da Universidade Federal de Viçosa (VIC) e no herbário Rioclarense (HRCB), Universidade Estadual Paulista, e identificadas pelo botânico Júlio A. Lombardisob o número de registro Pereira 01 (VIC: 36.631).

As folhas de oliveira (Oleaeuropaea L.) foram submetidas à secagem em estufa de ventilação forçada, sob temperatura constante de $40^{\circ} \mathrm{C}$ até estabilização do peso para obter a matéria seca para os materiais supracitados.

O material desidratado foi triturado com gral e pistilo; neste procedimento foram utilizados $1,0 \mathrm{~kg}$ de folhas de Oliveira e submetido a uma extração por maceração em álcool etílico absoluto (PA) diluído em água destilada 1:1, conforme metodologia descrita porWoisky (1996).Ao final, foi verificado o rendimento do extrato de aproximadamente 200 gramas (20\%) e os mesmos foram armazenados em recipiente plástico opaco, em presença de agente dessecante.

O flavonoide Morina (95\% de pureza), 3-(4,5-dimetil-2-tiazol) 2,5-difenil-2-H-brometo de tetrazom (MT), cisplatina, laranja de acridina e brometo de etídio foram comprados da Sigma Chemistal (St. Louis, MO, SUA).

\section{Linhagem e cultivo celular}

A linhagem de célula H460 foi obtida do Laboratório de Biologia do Reconhecer do Centro de Biociências e Biotecnologia da Universidade Estadual Norte Fluminense (Campos dos Goytacazes, RJ). As células foram cultivadas em meio D-MEM F12 (Gibco, BRL), conforme metodologia descrita por (Horn et al., 2013).

\section{Ensaio MTT e LDH}

Alinhagem de célula $\mathrm{H} 460$ foram plaqueadas em volume de $100 \mu \mathrm{L} /$ poço $\left(1 \times 10^{6} \mathrm{cels} / \mathrm{mL}\right)$ em 
placas de 96 poços, tratadas com o flavonóide morina e o extrato de oliveira nas concentrações finais de 50, 100, 200, 400 e $800 \mu \mathrm{M}$ e $\mu \mathrm{g} / \mathrm{mL}$ para os testes de viabilidade celular com MTT -3-(4,5-dimetil-2-tiazol) 2,5-difenil-2-H-brometo de tetrazolium (MTT), conforme metodologia descrita por Horn et al. (2013). Parte do sobrenadante das culturas foi utilizada para a dosagem da lactato desidrogenase (LDH). A determinação da enzima LDH é proporcional ao número de células mortas por necrose in vitro. Para quantificação da LDH foi utilizado o KIT DOLES.

\section{Análise de apoptose por Microscopia de fluorescência}

As células $\mathrm{H} 460$ foram incubadas por 12 , 24, 36 horas para o composto morina, e 12, 24, 36 e 48 horas para o extrato de oliveira. Não foi realizado o tempo de 48 horas para morina, pois todas as células testadas encontravam-se mortas no período de 38 horas. A seguir foram coradas com uma solução de $10 \mu \mathrm{g} / \mathrm{mL}$ laranja de acridina (Sigma) e $10 \mu \mathrm{g} / \mathrm{mL}$ de brometo de etídio (Sigma), conforme metodologia descrita por (Horn et al., 2013).

Análise do potencial de membrana mitocondrial por citometria de fluxo

O potencial de membrana mitocondrial foi analisado utilizando o marcador catiônico lipofílico fluorescente JC-1 (iodeto de 5,5',6,6'-tetracloro1,1',3,3'-tetraetilbenzimidazolilcarbocianina). As linhagens tumorais foram tratadas com o composto morina $(400 \mu \mathrm{M})$ e o extrato de oliveira $(800 \mu \mathrm{g} / \mathrm{mL})$ e as células foram incubadas por 48 horas em estufa $\left(37^{\circ} \mathrm{C} \mathrm{e} 5 \%\right.$ de $\left.\mathrm{CO}_{2}\right)$, conforme metodologia descrita por (Horn et al., 2013).

\section{Análise estatística}

Os resultados foram expressos por média \pm desvio padrão, analisados de forma independente. Os ensaios foram analisados por ANOVA - Oneway - seguido de Tukey utilizando o programa GraphPad versão 5.0. As diferenças significativas foram consideradas como $P<0,05$.

\section{RESULTADOS \\ Determinação da viabilidade da célula $\mathrm{H} 460$ tratada com o composto morina e extrato de oliveira (MTT) \\ Para investigar o efeito do flavonóide} morina e do extrato de oliveira na viabilidade celular da linhagem tumoral $\mathrm{H} 460$, as células foram expostas a concentrações crescentes das drogas testadas por 48 horas e a viabilidade celular foi mensurada através do ensaio de MTT. Pode-se verificar na figura 02 , que o composto morina e o extrato de oliveira mostraram-se capazes de reduzir a viabilidade da linhagem $\mathrm{H} 460$ de maneira dependente de concentração para as concentrações 200,400 e $800 \mu \mathrm{M}$ e $\mu \mathrm{g} / \mathrm{mL}$, respectivamente. A morina reduziu a viabilidade celular das

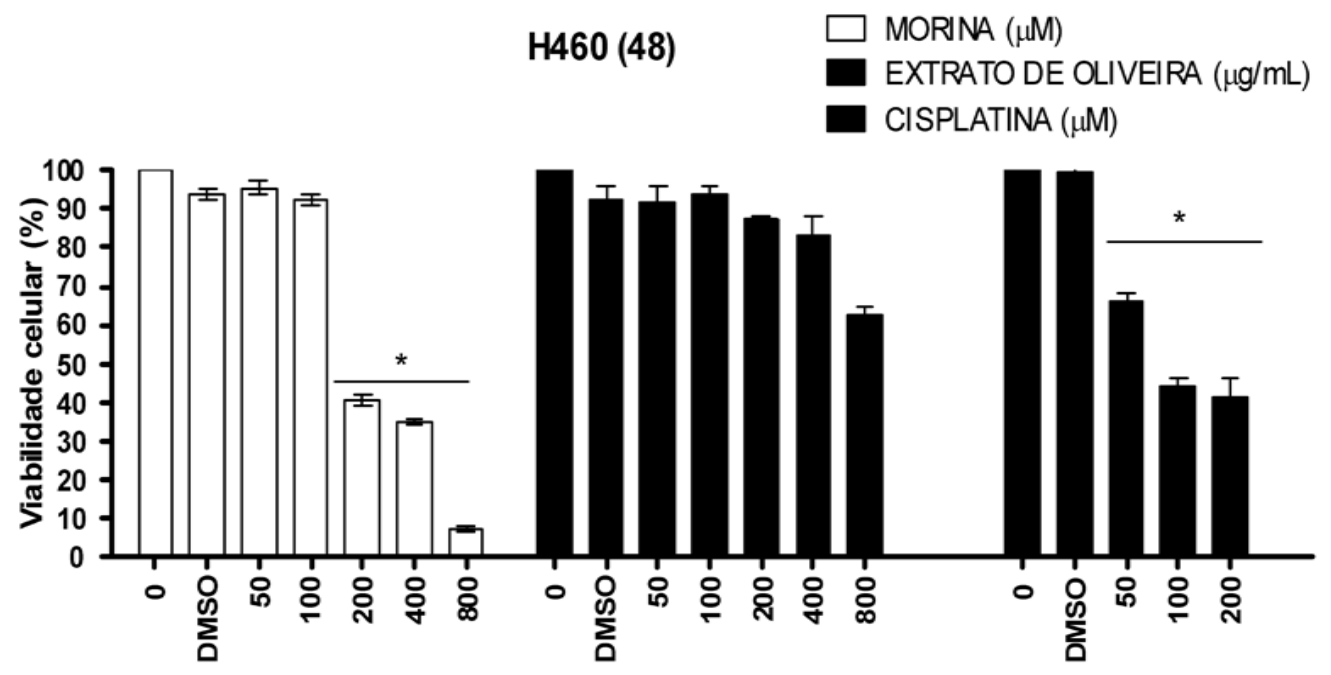

\section{Concentrações}

FIGURA 2.Efeito citotóxico do composto morina, extrato de oliveira e cisplatina (controle positivo) contra a célula humana $\mathrm{H} 460$, após 48 horas de incubação através do ensaio colorimétrico utilizando MTT $(n=3)$. O zero significa o controle negativo do teste (células e meio de cultivo). A concentração de DMSO foi de $1 \%$. ${ }^{*} P<0.05$; valor estatisticamente significante em relação ao controle negativo (zero) pelo teste Tukey. 
células H460 para $40,4 \pm 4,21 \%, 34,9 \pm 3,05 \%$ e $7,22 \pm 1,54 \%$ nas concentrações de 200,400 e800 $\mu \mathrm{M}$, respectivamente, quando comparada ao controle negativo $(100 \%)$ e o extrato de oliveira reduziu a viabilidade celular das células $\mathrm{H} 460$ para $83,35 \pm 15,18 \%$ e $62,37 \pm 2,85 \%$ nas concentrações de 400 e $800 \mu \mathrm{g} / \mathrm{mL}$, respectivamente, quando comparada ao controle negativo (100\%).

Como controle positivo, foi avaliado o efeito citotóxico do composto cisplatina $(\mu \mathrm{M})$ para linhagem de célula $\mathrm{H} 460$ que reduziu a viabilidade das células testadas para $44,41 \pm 5,51 \%$ e $41,63 \pm 13,7 \%$ nas concentrações de 100 e $200 \mu \mathrm{M}$, respectivamente. Pelos dados apresentados na figura 02, observa-se que a morina $(40,4 \pm 4,21 \%)$ apresentou valor na redução da viabilidade celular para célula testada semelhante ao valor da cisplatina(41,63 $\pm 13,7 \%)$, para a concentração de $200 \mu \mathrm{M}$. Entretanto, o $\mathrm{CE}_{50}$ da cisplatina $(55,87 \pm 1,10 \mu \mathrm{M})$ é 4 vezes menor que $\circ \mathrm{CE}_{50}$ da morina $(220,30 \pm 1,08 \mu \mathrm{M})$, sendo portanto, mais ativa (Tabela 01). Pesquisas mostram que a morina possui baixa toxicidade ao organismo, contrapondo-se a cisplatina que apresenta resultados limitados pelos efeitos colaterais como náusea, vômitos e nefrotoxicidade (Yazici et al., 2012; Said \& Tsimberidou, 2014). Para o extrato de oliveira, não foi possível calcular o $\mathrm{CE}_{50}$ por não atingir o limiar de $50 \%$, apresentando efeito na dose de $800 \mu \mathrm{g} / \mathrm{mL}$ para o método de MTT (Figura 02).

TABELA 1. CE50 $(\mu \mathrm{M})$ da morina e do extrato de oliveira sobre a viabilidade celular baseado no ensaio de citotoxicidade celular por MTT.

\begin{tabular}{l|l}
\hline Drogas Testadas & CE50H460 \\
\hline Morina $(\mu \mathrm{M})$ & $220,30 \pm 1,08$ \\
Extrato de oliveira $(\mu \mathrm{g} / \mathrm{mL})$ & $>800$ \\
Cisplatina $(\mu \mathrm{M})$ & $55,87 \pm 1,10$ \\
\hline
\end{tabular}

\section{Avaliação da viabilidade celular pela liberação da lactato desidrogenase.}

A enzima LDH liberada pelas células neoplásicas H460 foi mensurada em espectrofotômetro após 48 horas de tratamento com o flavonóide morina, e extrato de oliveira em diferentes concentrações 50, 100, 200, 400, 800 $\mu \mathrm{M}$ e $\mu \mathrm{g} / \mathrm{mL}$, respectivamente. Na figura 03 pode-se observar que as linhagens tratadas com o composto morina apresentaram aumento de liberação da enzima LDH nas concentrações 100, 200, 400 e $800 \mu \mathrm{M}$, indicando que foram capazes de induzir a liberação de LDH na linhagem de célula testada de maneira concentração dependente, significando que houve ruptura da membrana plasmática nas maiores concentrações o que confirma a redução da viabilidade celular pelo método de MTT. Já as células tratadas com o extrato de oliveira foram capazes de liberar estas enzimas somente na concentração $800 \mu \mathrm{g} / \mathrm{mL}$ confirmando o resultado de viabilidade celular pelo MTT (Figura 02).

Apesar da presença de LDH liberada no meio confirmar o resultado de viabilidade celular pelo ensaio de MTT, sua ausência não invalida o resultado positivo deste teste, uma vez que, as membranas das células mortas por apoptose não são rompidas.

Avaliação do mecanismo de morte celular induzida pela morina e pelo extrato de oliveira (microscopia de fluorescência)

A figura 04 mostra a porcentagem de apoptose induzida pelo composto morina e pelo extrato de oliveira na linhagem de célula tumoral humana H460. Observa-se, através dos gráficos, que o composto morina foi capaz de induzira apoptose na célula H460nas concentrações 200, 400 e $800 \mu \mathrm{M}$,nos períodos de tempo 24 e 36 horas. As taxas percentuais de indução de apoptose foram para $12,90 \pm 0,6 \%$ e $37,95 \pm 6,1 \%$ para 24 e 36 horas na concentração de $200 \mu \mathrm{M} ; 27,77 \pm 9,45 \%$ e $58,01 \pm 0,73 \%$ para 24 e 36 horas na concentração de $400 \mu \mathrm{M}$ e $57,3 \pm 3,85 \%$ e $100 \%$ para 24 e 36 horas na concentração de $800 \mu \mathrm{M}$, respectivamente (Figura 04).

As taxas percentuais de indução de apoptose para o extrato de oliveira foram $17,61 \pm 3,22 \% ; 14,95 \pm 3,00 \%$ e $22,42 \pm 2,05 \%$ para 24, 36 e 48 horas na concentração de $400 \mu \mathrm{g} / \mathrm{mL}$ e $24,45 \pm 6,90 \% ; 38,15 \pm 12,30 \%$ e $70,49 \pm 5,91 \%$ para 24, 36 e 48 horas na concentração de $800 \mu \mathrm{g} /$ $\mathrm{mL}$, respectivamente (Figura 05).

\section{Alteração do potencial de membrana mitocondrial}

Para as células da linhagem submetida ao tratamento com morina e extrato de oliveira e o controle positivo (cisplatina) foram verificados um deslocamento da população celular do quadrante "C" para o quadrante " $D$ ", onde se observam células com dissipação do potencial mitocondrial de membrana (FL1) nas concentrações 200 e 400 $\mu \mathrm{M}$ para morina em 36 horas e 400 e $800 \mu \mathrm{g} / \mathrm{mL}$ para o extrato de oliveira em 48 horas. Conforme observado na figura 05 , o composto morina foi capaz de reduzir o potencial de membrana mitocondrial em mais de $50 \%$ na concentração de $400 \mu \mathrm{M}$ em 36 horas e o extrato de oliveira foi capaz de reduzir o potencial de membrana mitocondrial acima de $50 \%$ na concentração de $800 \mu \mathrm{g} / \mathrm{Ml}$ em 48 horas (Figura 06 e 07).

Rev. Bras. PI. Med., Campinas, v.17, n.4, supl. I, p.798-806, 2015. 


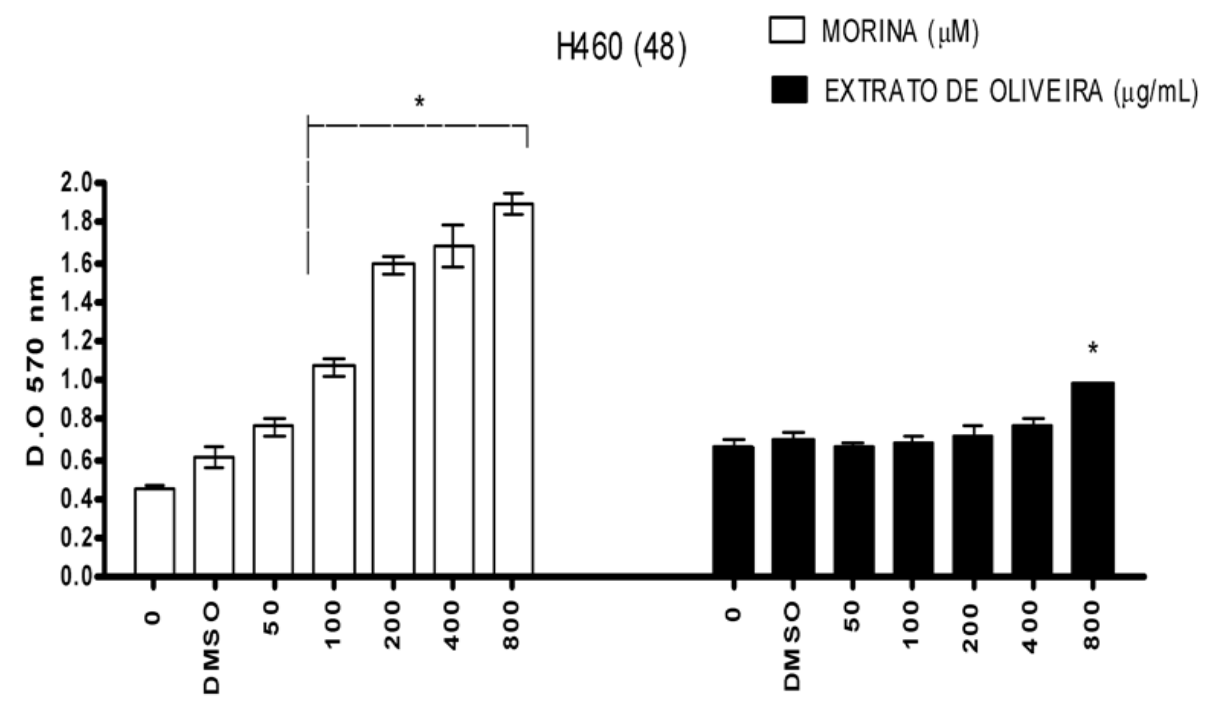

Concentrações

FIGURA 3.Avaliação da liberação da LDH (desidrogenase láctica). Células da linhagem H460 foram tratadas com diferentes concentrações do composto morina e extrato de oliveira durante 48 horas e avaliadas quanto à quantidade de LDH liberada $(n=3)$. O zero significa o controle negativo do teste (células e meio de cultivo). A concentração de DMSO foi de $1 \%$. ${ }^{*} P<0.05$, valores estatisticamente significantes em relação ao controle negativo (zero) pelo teste Tukey.

MORINA (H460)

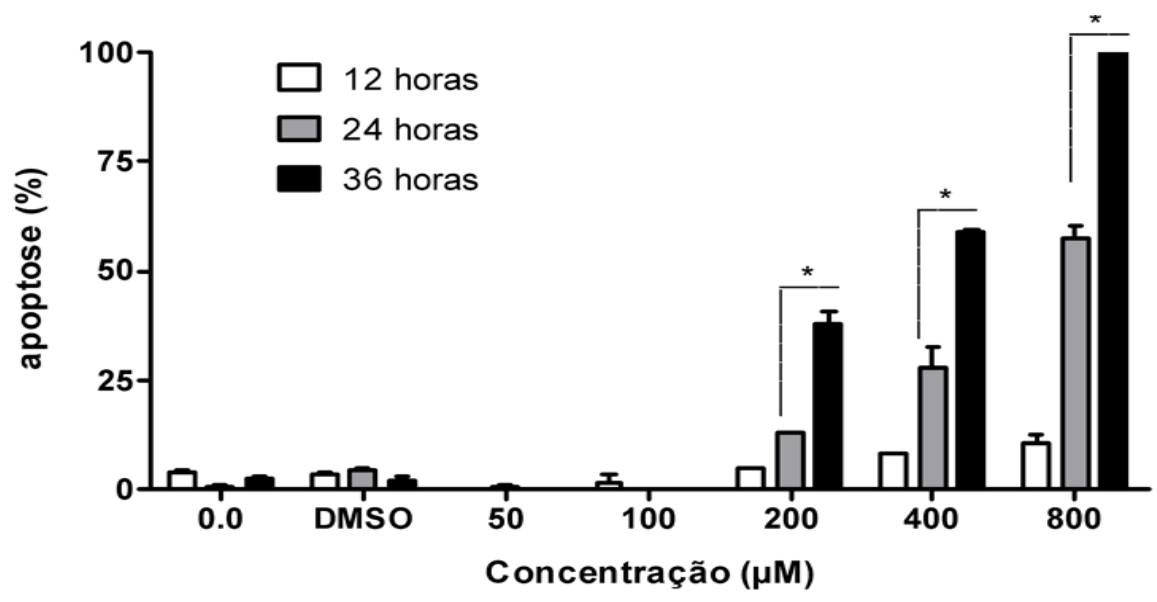

FIGURA4.Porcentagem de apoptose induzida pelo composto morina na linhagem neoplásica H460 determinada por microscopia de fluorescência em três tempos 12, 24, 36 horas $(n=2)$. O zero significa o controle negativo do teste (células e meio de cultivo). A concentração de DMSO foi de $0,2 \%$. ${ }^{*} P<0.05$, valores estatisticamente significantes em relação ao controle negativo (zero) pelo teste Tukey.

\section{DISCUSSÃO}

Vários estudos comprovaram que a maioria dos fármacos antitumorais promovera a morte das células cancerígenas através do mecanismo de apoptose, um tipo de morte celular programada. Deste modo, drogas que promovem apoptose como via de indução de morte celular são fortes candidatos a fármacos com ação antitumoral (Onrubia et al., 2013).

No que se refere à viabilidade celular, ambos,morina e extrato de oliveira reduziram a viabilidade da linhagem tumoral H460 de maneira dependente de concentração quando comparados com células não tratadas. Seus maiores resultados foram para a concentração de $800 \mu \mathrm{M}$ e $\mu \mathrm{g} / \mathrm{mL}$, respectivamente.

O extrato de folhas de oliveiras foi testado por (Ko et al., 2009) e apresentou resultados de atividade antitumoral para linhagem de células $\mathrm{H} 460$ superior a $70 \%$. Apesar da flavona morina apresentar a atividade antitumoral, sua eficiência frente a linhagem H460 ( $\left.\mathrm{CE}_{50}: 220,30 \pm 1,08 \mu \mathrm{M}\right)$ mostrou-se 


\section{EXTRATO DE OLIVEIRA (H460)}

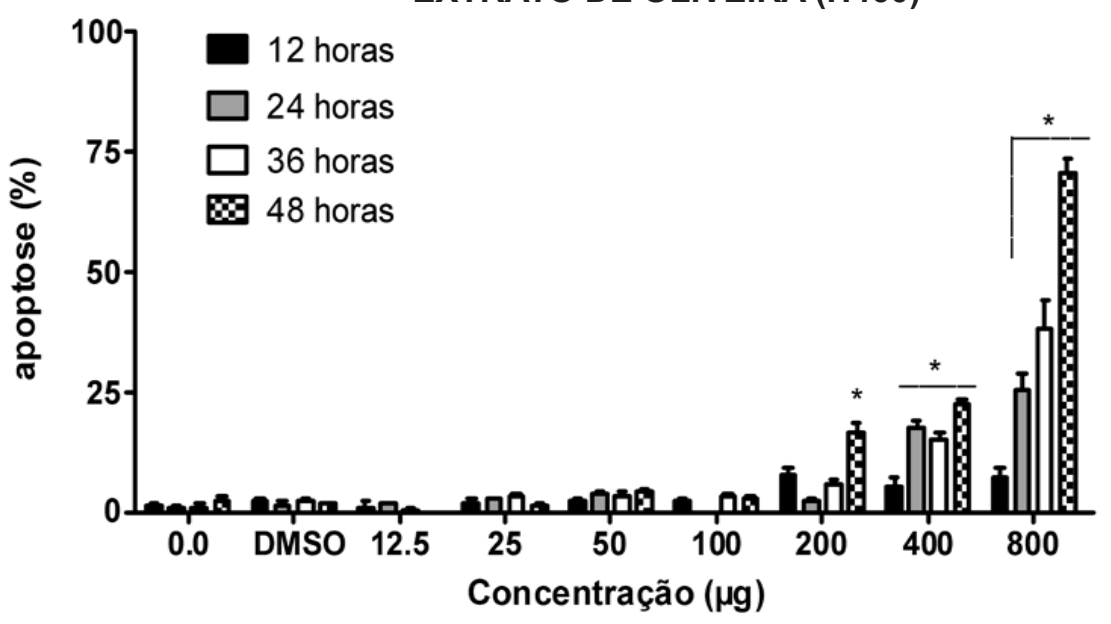

FIGURA 5. Porcentagem de apoptose induzida pelo extrato de oliveira na linhagem neoplásica H460 determinada por microscopia de fluorescência em quatro tempos 12, 24, 36 e 48 horas $(n=2)$. O zero significa o controle negativo do teste (células e meio de cultivo). A concentração de DMSO foi de $0,2 \%$. ${ }^{*} P<0.05$, valores estatisticamente significantes em relação ao controle negativo (zero) pelo teste Tukey.
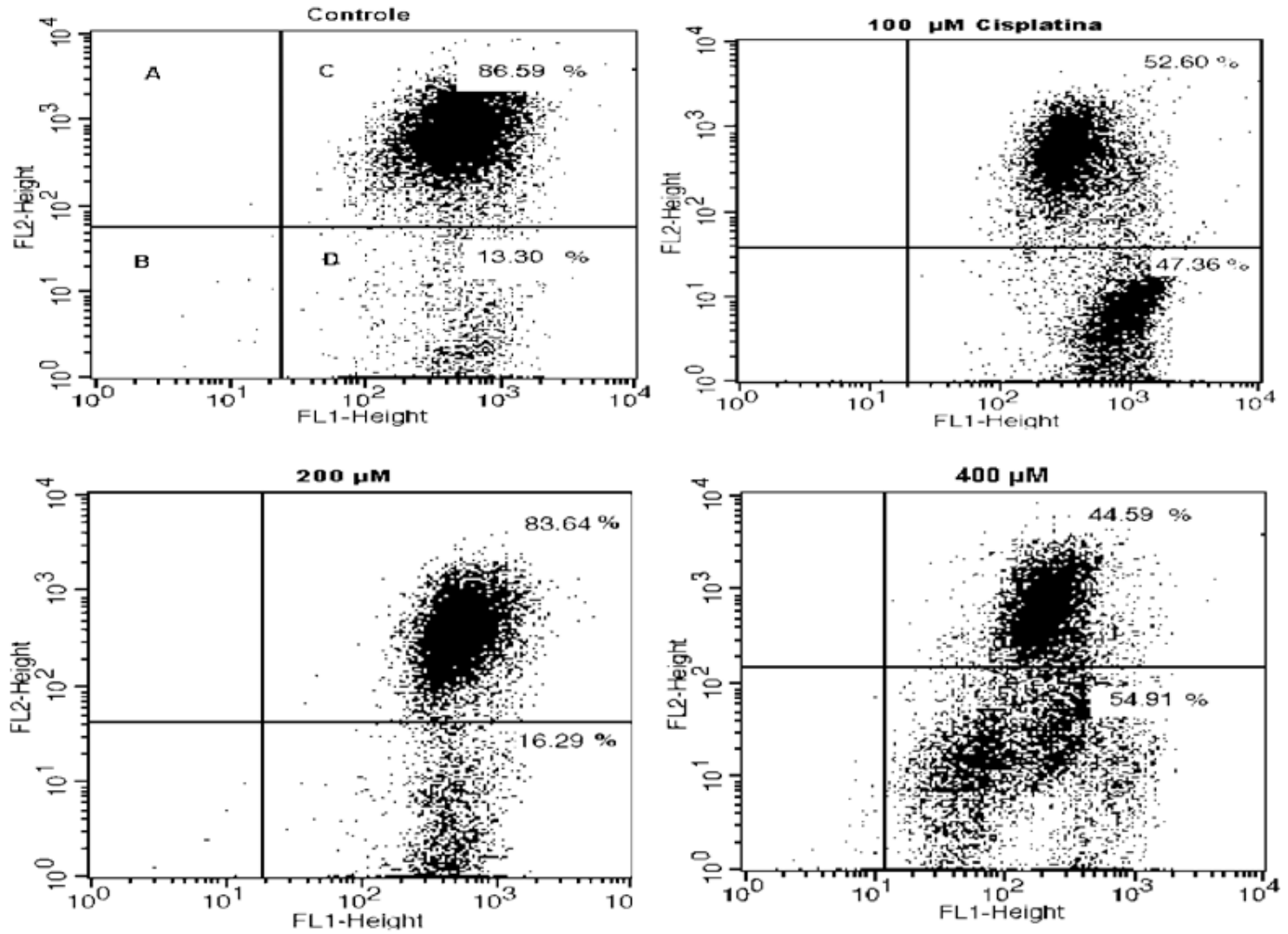

FIGURA 6.Dot-plots da análise do potencial de membrana mitocondrial, por citômetria de fluxo, para células H460 submetidas à incubação de 36 horas com o composto morina.

baixa quando comparada aos flavonoides fisetina, apigenina, quercitina, kaemferol pesquisados em células pulmonares de Lewis, que apresentaram $\mathrm{CE}_{50}$ inferiores a $50 \mu \mathrm{M}$ (Touil et al., 2009).
Trabalhos comprovam que o flavonóide morina é capaz de inibir a proliferação celular em vários tipos de células carcinogênicas inibindo o ciclo celular em vários tumores como carcinoma oral e 

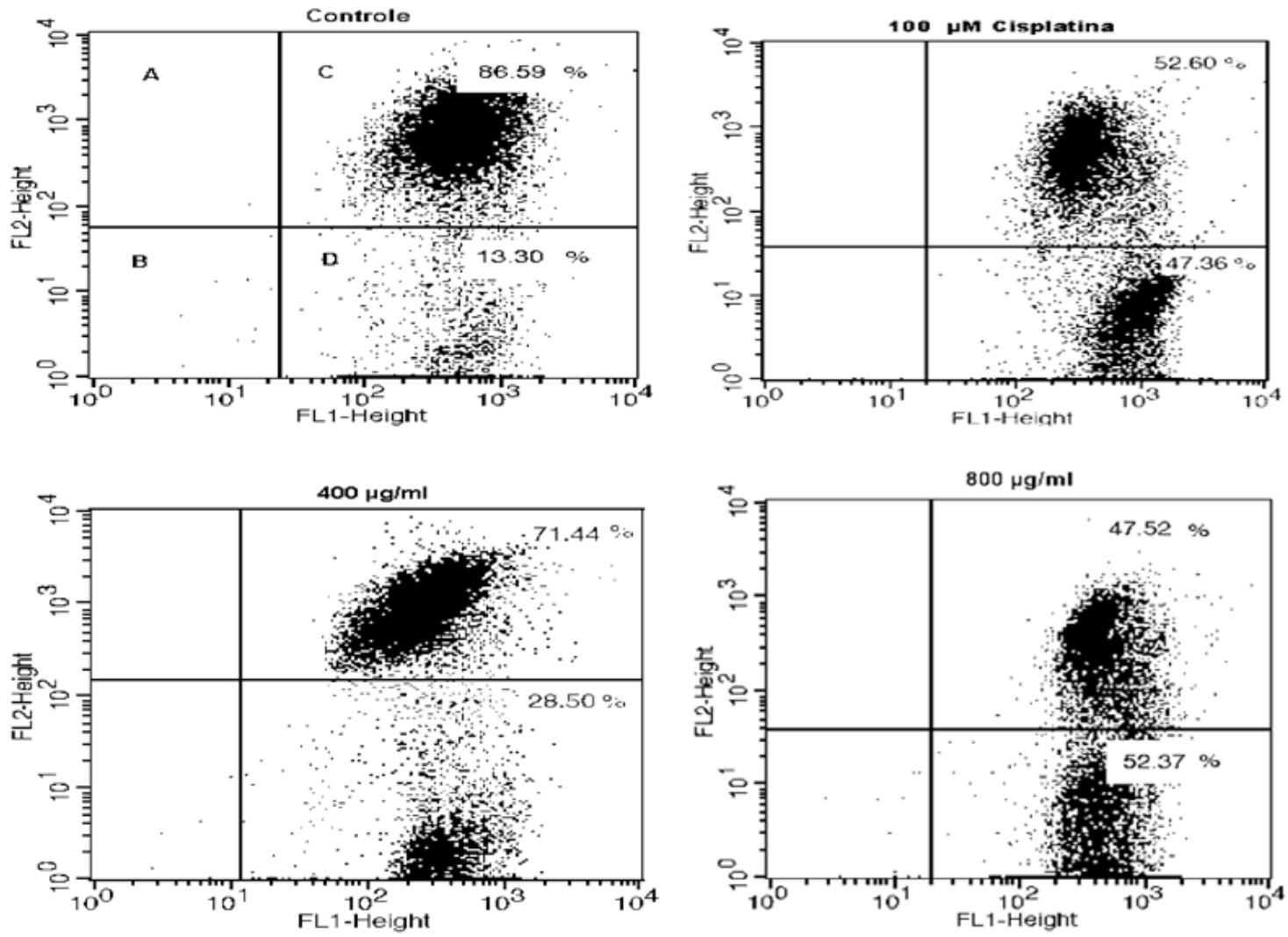

FIGURA 7. Dot-plots da análise do potencial de membrana mitocondrial, por citometria de fluxo, para células H460 submetidas à incubação de 48 horas com o extrato de folhas de oliveira.

em hepatócitos humanos (Kilani-Jaziri et al., 2011; Jash \& Brahmachari, 2013).

O extrato de oliveira possui uma quantidade apreciável de compostos fenólicos (GranadosPrincipal et al., 2010; Burattini et al., 2013). Inúmeros estudos demonstram que o flavonóide luteolina, um dos compostos presente no extrato de oliveira, apresentou vários mecanismos bioquímicos de ação antitumoral tais como o bloqueio do ciclo celular na fase $\mathrm{G} 1 / \mathrm{S}$, redução da atividade da ciclina D1 via fosforilação da proteína e degradação proteassomal (Ong et al., 2010).

As caspases desempenharam um papel crítico na iniciação de apoptose (Chen \& Debnath, 2009). Pesquisas demonstraram que morina induziu apoptose atraves da ativação da via intrinseca mitocondrial, liberou o citocromo $\mathrm{C}$, ativou caspases-9 e -3 (Graf et al., 2014). Foi observado que o flavonóide morina e o extrato da folha de oliveira promoveram apoptose na linhagem H460 através da caspase-3, uma proteína efetora da apoptose.

Através da alteração do potencial de membrana foi possível observar que a morina e o extrato de oliveira induzirão apoptose pela via mitocondrial (Portt et al., 2010). A apoptose pode ser dividido em via intrínseca e extrínseca.
No entanto, disfunções mitocondriais, incluindo a perda de potencial de membrana mitocondrial, a permeabilidade, transição e liberação do citocromo C da mitocôndria para o citosol, estão associadas com a apoptose (Whelan et al., 2010; Park et al., 2014). Trabalhos realizados por Liu et al. (2011) afirmam amorina pode induzir apoptose pela via intrínseca em células HL-60. Park et al. (2014) estudou os efeitos da morina sobre a família $\mathrm{Bcl}-2$ e concluíram que o flavonoide induziu apoptose em células humanas leucêmicas U937.

Estudos In vitro com a linhagem de câncer de colo HT29 demonstraram que o extrato do fruto da oliveira inibiu a proliferação sem citotoxidade e induziu a apoptose pela via intrínseca mitocondrial (Amber et al., 2011).

Os resultados obtidos mostram que o flavonóide morina e o extrato da folha de oliveira são promissores na busca por novos agentes antineoplásicos, no entanto mais testes devem ser realizados a fim de elucidar as vias de indução de apoptose promovidas tanto pelo morina quanto pelo extrato de oliveira nesta linhagem neoplásica.

\section{CONCLUSÃO}

O presente estudo demonstrou que o flavonóide morina e o extrato de folhas de oliveira 
apresentaram atividade citotóxica contra a linhagem de célula de pulmão humana $\mathrm{H} 460$, diminuindo a viabilidade celular de maneira dependente de concentração, apresentando $\mathrm{CE}_{50}$ de 220,3 $\pm 1,08 \mu \mathrm{M}$ para morina. Os resultados de microscopia de fluorescência e citômetria de fluxo permitiram concluir que o composto morina e o extrato de oliveira induziram morte celular por apoptose alterando a função mitocondrial das células $\mathrm{H} 460$, sendo morina mais efetivo de maneira tempo e concentração dependente. Por fim, os resultados sugeriram que o flavonóide morina e o extrato da folha de oliveira são promissores na busca de fármacos antineoplásicos por alterarem a função mitocondrial e induzirem morte celular por apoptose nas células $\mathrm{H} 460$.

\section{AGRADECIMENTOS}

DBB, UENF

Rede toxifar da FAPEMIG, CAPES, UFV,

\section{REFERÊNCIAS}

AL-NUMAIR, K.S. et al., A flavonoid, prevents lysosomal damage in experimental myocardial ischemic rats. Journal of Medicinal Plants Research, v.6, n.18, p.3445-3449, 2012.

AMADO, N.G. et al., Flavonoids: potencialWnt/beta-catenin signaling modulatiors in câncer. Life Scences,v.89, n.15-16, p.545-54, 2011.

AMBER, J. et al. A pilot study on the DNA-protective, cytotoxic, and apoptotic-inducing properties of olive-leaf extracts. Mutation Research, v.723, n.2, p.165-70, 2011.

ATTOUB, B. et al., Inhibition of cell survival, invation, tumor growth and histone deacetylase activity by the dietary flavonoid luteolin in human epithelioid câncer cells. European Journal of Pharmacology, v.651, n.1-3, p.18-25, 2011.

BLUM, D. et al., Cancer cachexia: a systematic literature review of itens and domains associated with involuntary weight loss in cancer. Critical Review in Oncology/ Hematology, v.80, n.1, p.114-44, 2011.

BULOTTA, S.; et al., Beneficial effects of the olive oil phenoliccomponents oleuropein and hydroxytyrosol:focus on protection against cardiovascular andmetabolic diseases. Journal of Translational Medicine,v.12, n.219, p. 1-9, 2014.

BURATTINI, S. et al., Anti-apoptotic activity of hydroxytyrosol and hydroxytyrosyl laurate. Food and Chemical Toxicology, v.55, p.248-256, 2013.

CHEN, N.; DEBNATH, J. Autophagy and tumorgenesis. FEBS Letters, v.584, n.7, p.1427-1435, 2009.

GRAF, R.P. et al., Caspase-8 as a Regulator of Tumor Cell.Motility Current Molecular Medicine, v.14, n.2, p.246-54, 2014.

GRANADOS-PRINCIPAL, S., et al., Hydroxytyrosol: from laboratory investigations to future clinical trials. Nutrition Review, v.68, n.4, p.191-206, 2010.
HARTWELL, D. et al., Topotecan for relapsed small cell lung cancer: Asystematic review and economic evoluation. Cancer Treatment Review, v.37, p.242249, 2011.

HOLENRIEDER, S.; STIEBER, P. Circulating apoptotic markers in the management of non-small cell lung cancer. Cancer Biomark, v.6, n.3-4, p.197-210, 2010.

HORN, A. JR., et al., Highly efficient synthetic irondependent nucleases activate both intrinsic and extrinsic apoptotic death pathways in leukemia cancer cells. Journal InorgBiochemistry,v.128, p.38-47, 2013.

HUNG, J. et al., Didymin, a dietary flavonoid glycoside from citrus fruits, induces Fas-mediated apoptotic pathway in human non-small-cell lung cancer cells in vitro and in vivo. LungCancer, v.68, n.3, p.366-374, 2010.

INCA, Ministério da Saúde: Incidência do Câncer no Brasil. Disponível em http://www.inca.gov.br/ Acesso em: 12 de setembro de 2014.

ISIK, S. et al., Proliferative and apoptotic effects of olive extracts on cell lines and healthy human cells. Food Chemistry, v.134, n.1, p.29-36, 2012.

JASH, S.K.; BRAHMACHARI G. Recent progress in the research of naturally occurring flavonoids: A look throughJournal Organic Biomolecuar Chemistry, v.1, p.65-168. 2013.

KAEIDI, A. et al., Olive leaf extract attenuates early diabetic neurophatic pain through prevention of high glucose-induce. Journal Ethnopharmacology, v.136, n.1, p.188-96, 2011.

KILANI-JAZIRI S, et al., Flavones inhibit the proliferation of human tumor cancer cell lines by inducing apoptosis. Drug Chemical Toxicology, v.35, n.1, p.1-10, 2011.

$\mathrm{KO}$, K et al., Antioxidant, Antimicrobial, and Antiproliferative Activities of Olive (Olea europaea L.) Leaf Extracts. Food Science and Biotechnology, v.18, n.3, p.818-821, 2009.

LIANDA R L. P.; CASTRO R. N. Isolamento e identificação da morina em mel brasileiro de Apismellifera Química Nova v. 31, n. 6, p. 1472-1475, 2008.

LIU, J. et al., Targeting apoptotic and autophagic pathways for cancer therapeutic.Cancer Letters, v.300, n.2, p.105-114, 2011.

MOUNTZIOS, G. et al., Mechanisms of disease: signal transduction in lung cardiogenesis - a comparasion of smokers and never smokers. Nature Clinical PraticalOnology,v.5, p.610-618, 2008.

NASO, L.G. et al., Biological evaluation of morin and its new oxovanadium(IV) complex as 4 antio-xidant and specific anti-cancer agents. Chemico-Biological Interactions, v.206, n.2, p.1-13, 2013.

ONG. C. et al., Luteolin induces $\mathrm{G} 1$ arrest in human nasopharyngeal carcinoma cells via the Akt-GSK3ß-Cyclin D1 pathway. Cancer letters, v.298, n.2, p.167-175, 2010

ONRUBIA, M. et al., Bio processing of Plant in Vitro Systems for the Mass Production of Pharmaceutically Important Metabolites: Paclitaxel and its Derivatives. Current Medical Chemistry, v.20, n.5, p.880-891, 2013.

PARK,C. et al., Effects of pro-apoptotic Bcl-2 on morininduced apoptosis in human leukemia U937 cells. Europian Journal of Cancer, v.50, p.S45, 2014.

PICK, A. et al., Struture-activity relationships of flavonoids as inhibitors of breast cancer resistence protein (BCRP). Biorganic\& Medical Chemistry, v.19, n.6, p.2000- 
2012, 2011.

PORTT, L. et al., Anti-apoptosis and cell survival: a review. Biochimica et Biophysica Acta, v.18, n.3, p.238-59, 2010.

TAMIRU, W. et al., Evaluation of the effects of $80 \%$ methanolic leaf extract of Cayluseaabyssinica (fresen.) Fisch\&Mey. On glucose handling in normal, glucose loaded and diabetic rodents. BCM Comtemporany and Alternative Medicine, v. 12, n. 1, p. 151, 2012.

TOUIL, Y.S. et al., Flavonoid-induced morphological modifications of endothelial cells through microtubule stabilization.Nutrition Cancer, v. 61, n.3, p.310-21, 2009.

WHELAN, R.S. et al., Cell death in the pathogenesis of heart disease: mechanisms and significance. Annual
Reviews of Phisiology, v.72, p.45-59., 2010.

YUAN, Z. et al., Casticin induces caspase-mediated apoptosis via activation of mitochondrial pathway and upregulation of DR5 in human lung cancer cells. Asian Pacific Journal of Tropical Medicine,v.6, n.5, p.372-378, 2013.

YAZICI, Z. M. et al., Reduction of cisplatin ototoxicity in rats by oral administration of pomegranate extract. EuropeanArchives of Oto-Rhino-Laryngology, v. 269, n.1, p.45-52, 2012.

WOISKY, R. G. Método de controle químico de amostra de própolis. 1996. p.81. (Dissertação Área do conhecimento em insumos farmacêuticos) - Departamento de ciências farmacêuticas, Universidade de São Paulo, São Paulo. 